\title{
Ethos of location and its implication to the motivators of Global Games Jam participants
}

\author{
Nia Wearn \\ Staffordshire University \\ College Road \\ Stoke-on-Trent \\ Staffordshire ST4 2DE \\ n.h.wearn@staffs.ac.uk
}

\author{
Brian McDonald \\ Glasgow Caledonian University \\ Cowcaddens Road \\ Glasgow, Scotland \\ G4 OBA \\ Brian.McDonald@gcu.ac.uk
}

\begin{abstract}
In the paper research about the motivations of jammers at two British universities and established Global Jam Sites are compared and a larger scale research project is proposed, examining the effect of the academic ethos of a locations and the motivators of jammers taking part at that location. It outlines the methodology of the initial dual location study and suggests further research avenues.
\end{abstract}

\section{CCS Concepts}

Social and professional topics $\rightarrow$ Professional topics $\rightarrow$ Computing and business $\rightarrow$ Computer supported cooperative work

\section{Keywords}

Games Jams, Locations, Motivations,

\section{INTRODUCTION}

The Global Game Jam has established itself as the largest scale on site game jam event in the world, with 632 locations listed in the 2016 Jam [1] - a large proportion of these are held at educational institutions - universities or colleges. While in no way a stipulation to host a jam site, The Global Game Jam Frequently Asked Question acknowledges this as a logistics aspect "Schools have access to large labs and space that are not always available at studios. Educational institutions also have the best access to broadband Internet." Since the inception of the Global Game Jam many of the sites have hosted numerous jams and they have become part of the annual social fabric of a university.

Permission to make digital or hard copies of all or part of this work for personal or classroom use is granted without fee provided that copies are not made or distributed for profit or commercial advantage and that copies bear this notice and the full citation on the first page. Copyrights for components of this work owned by others than ACM must be honored. Abstracting with credit is permitted. To copy otherwise, or republish, to post on servers or to redistribute to lists, requires prior specific permission and/or a fee.

Request permissions from Permissions@acm.org. GJH\&GC '16, March 13 2016, San Francisco, CA, USA (C) 2016 ACM. ISBN 978-1-4503-4083-0/16/03 ...\$15.00 DOI: http://dx.doi.org/10.1145/2897167.2897176
Educational institutions also have a ready supply of likely jammers, the relevant technology and the space the ethos of the institution is likely to act as a motivator to the student's reasons for attending. Other research has looked at why the individual do or do not attend jams [2], or the organization structure of the jams [3] and its implications to the motivating factors of those taking part.

Also evident at every university is a guiding 'ethos', a mission statement or plan. These are written to shape the academic nature of the institution. They are integral to the planning of courses and classes and have a knock on effect to how any events are perceived by the participants.

Staffordshire University is an example of an established Global Game Jam site, having taken part in the annual event since 2010. In that time numbers of attendees at the jam at that location have grown significantly, from 40 participants in the initial jam to 423 registered in 2016. Organisation for the event at the Stafford Campus is conducted using a public Facebook event, open from the beginning of October the preceding year and shared widely via social media channels, including alumni and current student's groups, course Facebook pages and twitter. The Global Game Jam event at Staffordshire University is open to everyone 16+ and includes a large alumni contingent reuniting with previous team mates and peers.

The same public event is used for communication during the jam, acting as an on-line PA announcement board and a hub for any questions or issues.

\section{STAFFORDSHIRE UNIVERSITY ETHOS}

As an established University with a range of technical Games related courses, spanning from their inception in 2006 - It has an established selection of vocational based courses and a long history of team work within the modules on its courses. At present its Games Design department primarily uses Unreal Engine 4 on its courses although there are also strands on awards that focus on other games engines such as Unity and creating games using traditional programming languages such a $\mathrm{C}++$ and $\mathrm{C \#}$. There are also courses with 2D or 3D art focus. In the 2015/16 academic year it has over 700 students studying a degree course, both undergraduate and post graduate with Games in the title.

In 2012 The University promoted a series of graduate attributes called 'The Staffordshire Graduate' [4] listing three 'life skills' Employability, Enterprise and Entrepreneurship and six graduate attributes comprising of 'Professional', Global Citizen', 'Teamwork', 'Life Long Learner', 'Reflective and Critical' and 
'Discipline Expert'. Since their inception they have been integrated into core Computer Games Design modules.

\section{EMERGENT RESEARCH USING SOCIAL MEDIA}

Since students use Facebook on a day to day basis for social communication, and increasingly for communication on group projects within the university it aligns well for us to use it as a social facilitator too. Since the event is 'open' and promoted for as long as certain topics are posted periodically to keep engagement high and lessen the chance that possible jammers will sign up for the event and subsequently not show up.

As part of the buildup and chatter to the event a poll was posted [5] asking 'Out of interest - what's your motivation for taking part in the games jam this year?' initially it was posted as a throw away aspect purely meant to engage jammers in conversation and increase the 'hype' in the run up to the jam. Posted on the $19^{\text {th }}$ January 2016 and allowing participants to add their own answers if they desired. Some initial answers were primed onto the poll including 'Portfolio Building', 'Networking' and 'Working with my Friends' but on posting the poll it was opened up to the possible pool of 686 invited, interested or attending Facebook users.

Users are free to select as many options are they feel are relevant to them and all in 578 responses were recorded. They can only select each response once, but can select multiple answers. New responses can be added as user desire and options can be selected and deselected at will. Facebook users can also see the answers their friends have selected, which may contribute to the popularity of some choices. While it is not the most methodologically sound form of gathering data it can act as a useful gauge and the social and speedy nature of it can gather a lot of participation quickly. The poll automatically organizes the most popular responses from the top down and other participants can see who of their friends have selected which options. This accounts for the inclusion of references from previous jams and local references.

The 2015 Global Game Jam at the same site had 321 Jammers so numbers of participants was expected to be high. Their high engagement with social media and Facebook also suggested that there would be a good number of results to the poll. It should be noted that by engaging with the poll the users also let their Facebook friends know of the poll, irrespective of if they are signed up to the event. This could allow people uninterested in the event to register a choice, but this is unlikely to have happened or have a significant effect on the results.

There are limitations to using Facebook to gather data, the immediacy of the results is also an issue, where a group mentality can take over a poll without the researcher being able to control the direction of the poll. At current time of writing there is no way to directly limit to group that engage with any one poll, since they can be shared freely and friends of friends are notified when someone they know participates in a poll. In this instance there is no way to guarantee that all of the responders attended the Staffordshire University event, but it's highly likely that they did.

\section{MOTIVATING FACTORS}

Many of the participants at the Staffordshire University jam return year on year and have accrued 'veteran' status. References to previous jams, events and the games submitted are woven into entries and teams. That such references are added to the Facebook poll are not surprising and reinforce the social nature of the platform. As the poll matured during the week before the jam it was clear there was an interesting research element emerging.

Since the list of possible topics is user generated, but without noting when additions are added the list of possible answers remains in a state of flux. Within a few days of being posted the following list had emerged. They are listed here with any reference notes that are applicable.

Table 1. Motivating Factors and References

\begin{tabular}{|c|c|}
\hline $\begin{array}{l}\text { Motivating Factor as Listed on } \\
\text { the Facebook Poll }\end{array}$ & Reference and notes \\
\hline Working with my friends & $\begin{array}{l}\text { Teams are allowed to pre } \\
\text { form at the Staffordshire Uni } \\
\text { Site }\end{array}$ \\
\hline \multicolumn{2}{|l|}{ For the Fun } \\
\hline \multicolumn{2}{|l|}{ Portfolio Building } \\
\hline \multicolumn{2}{|l|}{ Alumni Coming Back to Staffs } \\
\hline \multicolumn{2}{|l|}{ Gain Experience as a Newbie } \\
\hline \multicolumn{2}{|l|}{ Develop skills for University } \\
\hline \multicolumn{2}{|l|}{ Trying out new ideas } \\
\hline \multicolumn{2}{|l|}{ Networking } \\
\hline \multicolumn{2}{|l|}{ Prove I could make a game } \\
\hline \multicolumn{2}{|l|}{ Actually Being Productive for once } \\
\hline $\begin{array}{l}\text { To Bring Back glory to Thurstman and } \\
\text { his trusty sidekick Squelch falcon' }\end{array}$ & In joke from a game at GGJ15 \\
\hline $\begin{array}{l}\text { improve communication skills in a pre- } \\
\text { existing team }\end{array}$ & $\begin{array}{l}\text { Added by a team that were } \\
\text { also working on an indie } \\
\text { game in their spare time }\end{array}$ \\
\hline $\begin{array}{l}\text { To be able to drink an unacceptable } \\
\text { amount of Southern Comfort }\end{array}$ & $\begin{array}{l}\text { Added mid jam (although } \\
\text { none of the jammers seems } \\
\text { intoxicated) }\end{array}$ \\
\hline Make a commercial release game & $\begin{array}{l}\text { Added by a jammer from a } \\
\text { team that had previously } \\
\text { made a commercial release } \\
\text { from a previous GGJ }\end{array}$ \\
\hline \multicolumn{2}{|l|}{ Force of Habit } \\
\hline \multicolumn{2}{|l|}{ Finding Non-Programmers } \\
\hline \multicolumn{2}{|l|}{ Helping People } \\
\hline $\begin{array}{l}\text { Expanding my knowledge on how to } \\
\text { summon demons }\end{array}$ & $\begin{array}{l}\text { Reference to the theme of } \\
\text { 'ritual' GGJ16 }\end{array}$ \\
\hline Ali's & $\begin{array}{l}\text { Local kebab house beloved by } \\
\text { students }\end{array}$ \\
\hline
\end{tabular}

It should also be noted that the Staffordshire University Stafford Campus is moving next year to Stoke-On-Trent, 20 miles away and that GGJ16 was billed as a farewell and a last hurrah to the Beaconside campus.

\section{STAFFS UNI POLL RESULTS}

The following chart shows the prevalence of responses to the questions asked in the motivating factors. It has been recreated to remove any question of detail who may have responded to the poll on the Facebook site but it is accurate to February $2^{\text {nd }} 2016-14$ days after it was originally posted and after the Global Game Jam had ended. 
Polls, and events remain open past the events end, however engagement in the event has dropped off considerably and there have been no new posts since February $1^{\text {st }} 2016$. Since the event has ended it would have dropped off Facebook users radars and newsfeeds and be listed in their past events but its unlikely to be further interacted with.

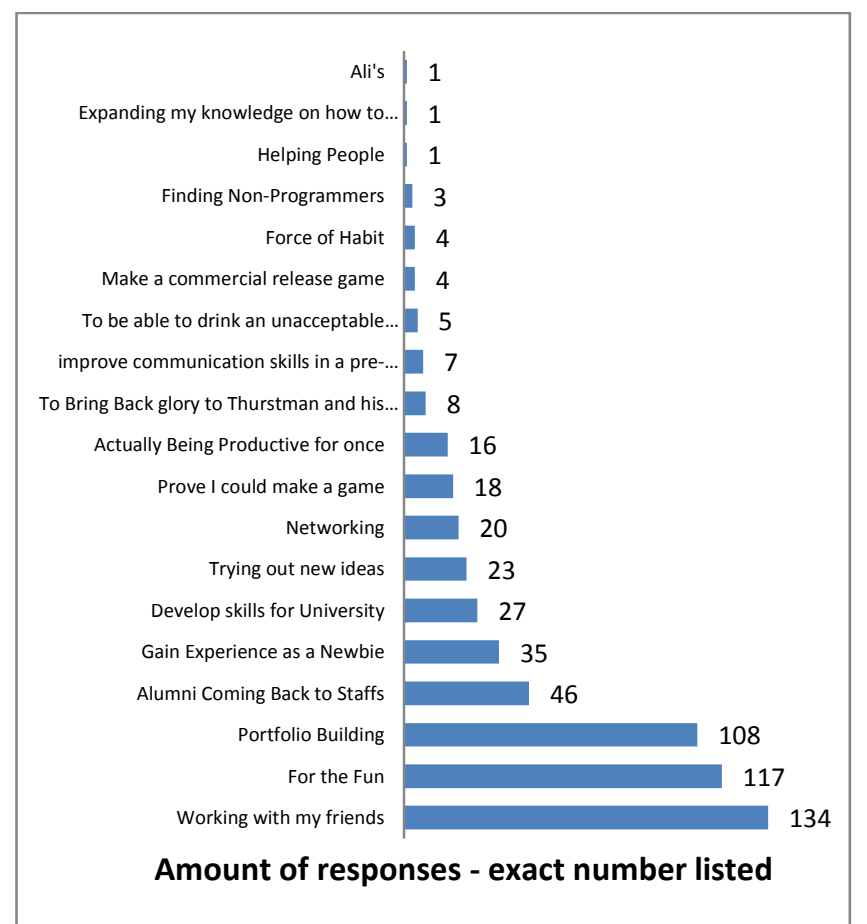

Figure 1. Chart with response data to Staffordshire University Facebook Poll

Of interest to the research was the sudden and noticeable leap in responses from 'Alumni coming back to Staffs' and Portfolio Building. Furthermore it was of interest that the number one response was 'Working with my friends'. It was felt these results required further investigation and results to compare them against.

\section{COMPANION STUDY AT GCU}

Since the results were available and viewable before the Global Game Jam began on January $29^{\text {th }}$ there was an opportunity to run a similar study at another UK institution also running a Global Game Jam site for 2016. Glasgow Caledonian University has run a Global Games Jam Site at its Glasgow site since 2009. In 2016 is had 143 registered participants but is also open to all. Its size of participants made it a natural companion for the study.

\section{ETHOS AT GCU}

GCU is very similar to University Staffordshire in many ways, it is an established vocational University with a range of Undergraduate Games related courses which had their inspection in a MSc in Game Technology, there are now three Games related Programmes being delivered at GCU, including Computer Games Software Development, Computer Games Design and Computer Games Art and Animation. Currently GCU uses Unity3D across the Games Programmes at Level 1 and the project modules through Level 1, $2 \&$ \& . Unreal Engine is used in the Game Content Design classes and more low level languages/APIs such as $\mathrm{C}++$ and OpenGL are used in Level 2 to 4 in the Computer Games Software Development Programme. In the 2015/16 academic year it has over 260 students are studying across the Games Programmes.

In 2013 GCU developed a 'Strategy for Learning (SfL)' [6], which is centred on a single goal: to develop graduates who are: Proficient in their discipline as well as entrepreneurial, confident, responsible and capable of fulfilling leadership roles in different organisations, cultural and global contexts. This strategy highlights the importance of 'a transformative approach to learning', 'flexible learning pathways and partnerships, particularly with colleges', 'digital learning', 'learning and teaching excellence' and 'student engagement'

\section{GCU METHADOLOGYAND RESULTS}

As opposed to using Facebook to gather the research the Glasgow study was conducted using a Google documents form, but with the same functionality in allowing participants multiple options and to add their own responses - although other participants wouldn't be able to see new additions to the form. The link to the form was e-mailed out to the participants. This negates the issues that Facebook polls can suffer since there was no question that the responders attended the event. This form method allows for much more control by the researcher, since the default option is not to allow participants to see the results in real-time, as a Facebook poll would allow.

The initial poll options were aligned with the 8 most popular motivations listed on the Staffordshire University but in a random order. No other data was recorded or included since it wasn't deemed necessary for the companion study.

Of the 143 registered jammers the link was sent out to 27 responses were recorded. They included two new 'options', a comedy one 'Chicks dig the jam' and a more considered response that the forthcoming jam would give the participant 'A different team/experience to the workplace' but the majority of responses dealt with the initial eight options:

'For the fun', 'Working with friends', 'Gaining experience', 'Portfolio Building', 'Trying out new ideas', 'Develop Skills for University', 'Networking', 'Alumni coming back'.

The initial results from the short GCU study did show a deviation from the Staffordshire University study

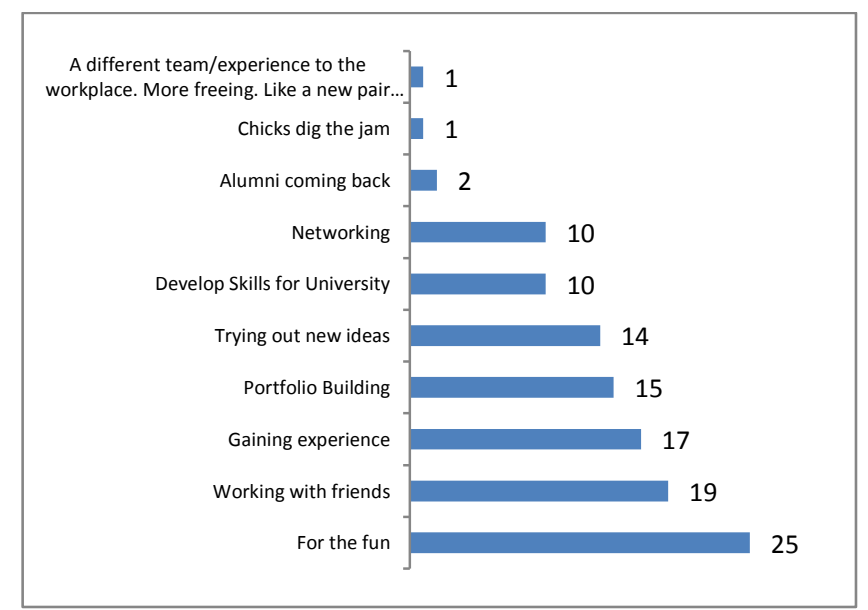

Figure 2. Chart with response data to GCU Google Poll 
Compared side by side these results show some notable differences, and are presented here with the most popular results from both polls in order of the most amount of responses. The most highly selected options are at the top.

Table 2. Comparing results

\begin{tabular}{|l|l|}
\hline Staffs jammers & GCU jammers \\
\hline Working with my friends & For the fun \\
For the Fun & Working with friends \\
Portfolio Building & Gaining experience \\
Alumni Coming Back to Staffs & Portfolio Building \\
Gain Experience as a Newbie & Trying out new ideas \\
Develop skills for University & Develop Skills for University \\
Trying out new ideas & Networking \\
Networking & Alumni coming back \\
\hline
\end{tabular}

\section{INITIAL RESULTS}

The side by side comparison shows the 'top rated' result differs at each institution - Staffordshire University jammers favouring working with their friends and Glasgow Caledonia jammers rating 'fun' the most. They also rate 'trying out new ideas' higher than that of Staffs Students while having less emphasis on Alumni returning to take part.

The only area point at which they mirror is the $6^{\text {th }}$ result 'Develop skills for University'. Both Staffordshire and Glasgow Caledonian have vocation, practical elements to their courses and the low ranking of this particular result implies that the course design and content at both universities, are succeeding in line with their relevant institutional academic ethos.

Some of these differences can be explained with ease - at Staffordshire University alumni are widely encouraged to come back and participate, but this is not the case at GCU. The Staffordshire University courses also have a large push on portfolio building across their vocational courses; especially in the final year and the Global Game Jam had been advertised to the students as a core portfolio building exercise. Team work, as outlined in the Staffordshire Graduate attributes has been interwoven into many modules, assessments and classes, but rarely do the students have a choice of who they work with. This might explain the 'working with my friends' option.

At GCU the students are told that the Global Game Jam is an excellent way to experiment with new games ideas and have fun, and that it is a chance to forgot about University work for a period of time. The recommendation of 'a transformative approach to learning' in the 'Strategy for Leaning' would look to support this statement.

\section{SUGGESTED FURTHER RESEARCH}

Since this was such a small study of only two institutions there is scope here for a larger scale research activity to happen before Global Game Jam 2017. Asking similar questions to participating jammers, on the run up to the event and in a similar relaxed way should produce relevant data as to the motivations of jammers. Asking before the event is key so as not to be confused with any post Global Game Jam related surveys and that the data retrieved isn't confused with any activities that happened during a jam.
At the same time recording the academic ethos of the location site, and noting any specific motivating factors there would start to build up a picture of why people choose to jam where they do. Does the proposed jam fulfil a need that is not answered elsewhere in the academic structure? This kind of study would be of interest especially in looking at regional, or global variations in jammers, and where jammers have a choice of location in an area. Other factors too such as team formation, and varying organizational structures would also play a part.

This study did not take into account the demographics of the participants at either site, since that level of data would requires a study of its own. It's possible that a deeper level study in to the different motivations of diverse demographics could be folded into any further research. If they are significantly different it would further help anyone looking to develop game jams that address specific issues.

The key element of understanding location ethos and how jams are framed and promoted to the participants should provide a key review of a maturing movement, and be of use to underdeveloped locations in planning future jam activities. This research would bring together a lot of the strands of exploration about jam locations and how jams are run that is already happening within the community.

\section{REFERENCES}

[1] Locations 2016 | Global Game Jam: 2016 Retrieved February 2, 2016, from Global Game Jam: http://globalgamejam.org/2016/jam-sites.

[2] Wearn, N., Fletcher, B., Vigurs, K. 2014. Contextualising nonattendance of eligible students to Global Game Jam locations. Second Workshop on the Global Game Jam, Foundations of Digital Games (Ft. Lauderdale, Florida 2014)

[3] Fowler, A., Lai, G., Khosmood, F., Hill, R. 2015. Trends in Organizing Philosophies of Game Jams and Game Hackathons. Foundations of Digital Games : Workshop on Game Jams, Hackathons and Game Creation Events (Pacific Grove, California, 2015)

[4] The Staffordshire Graduate: 2012. Retrieved February 4, 2016, from Staffordshire University - The Staffordshire Graduate: http://www.staffs.ac.uk/study/staffordshiregraduate/.

[5] Staffs Uni Global Games Jam 2016 poll. Retrieved February 2, 2016, from online facebook event: 2016: https://www.facebook.com/events/887838907972572/permalink/9 39562769466852/.

[6] Strategy for Learning 2015-20: 2016. Retrieved February 4, 2016, from Glasgow Caledonia University Strategy for Learning: http://www.gcu.ac.uk/engage/yourlearningexperience/strategyforl earning/. 